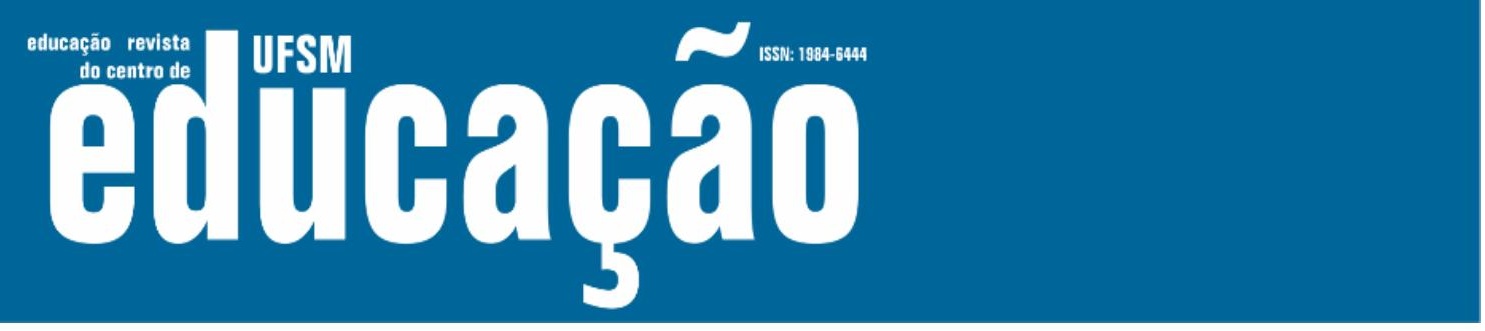

ISSN: 1984-6444 | http://dx.doi.org/10.5902/1984644436458

\title{
Movimento \#EleNão: reconhecimento e afirmação do ato de fala das mulheres na política
}

\author{
\#EleNão movement: acknowledgement and affirmation of women's \\ speech in politics
}

Maria Simone Vione Schwengber

Professora doutora na Universidade Regional do Noroeste do Estado do Rio Grande do Sul, ljuí, Rio Grande do Sul.

simone@unijui.edu.br - https://orcid.org/0000-0002-3583-1408

Naira Leticia Giongo Mendes Pinheiro

Doutoranda na Universidade Regional do Noroeste do Estado do Rio Grande do Sul, ljuí, Rio Grande do Sul.

nairaleticiagmendespinheiro@gmail.com - https://orcid.org/0000-0001-7920-1478

Recebido em 21 de janeiro de 2019

Aprovado em 28 de janeiro de 2020

Publicado em 24 de junho de 2020

\section{RESUMO}

O foco deste artigo está em discutir a emergência de vozes das mulheres brasileiras na contemporaneidade - da condição de silêncio e inferiorização das "subalternas" até as fraturas e, por consequência, as falas e manifestações nas redes digitais e nas ruas. No artigo, propõe-se um debate sobre as seguintes questões: como tem se dado a passagem entre 0 silêncio e a fala das mulheres nos espaços públicos? A partir de que condições? Como corpus das análises, utilizamos o movimento \#EleNão (2018). O percurso teórico-metodológico para a análise é inspirado na perspectiva foucaultiana do acontecimento discursivo. Das análises, destacamos que o movimento \#EleNão reatualiza a luta do reconhecimento do outro da política - Elas. \#EleNão emerge como política de performatividade, de ações corporais e gestuais de resistência, de exposição do direito de falar, de aparecer no sentido de existir, de lutar contra as precariedades das existências. \#EleNão produz sentidos de ação política no imaginário social brasileiro, isto é, reposiciona certa saída da condição das mulheres como subalternas que não falam. \#EleNão surge como espaço para tensionar/pensar o feminismo nos interstícios de suas igualdades e diferenças no campo das relações de gênero.

Palavras-chave: Mulheres; Fala; Reconhecimento. 


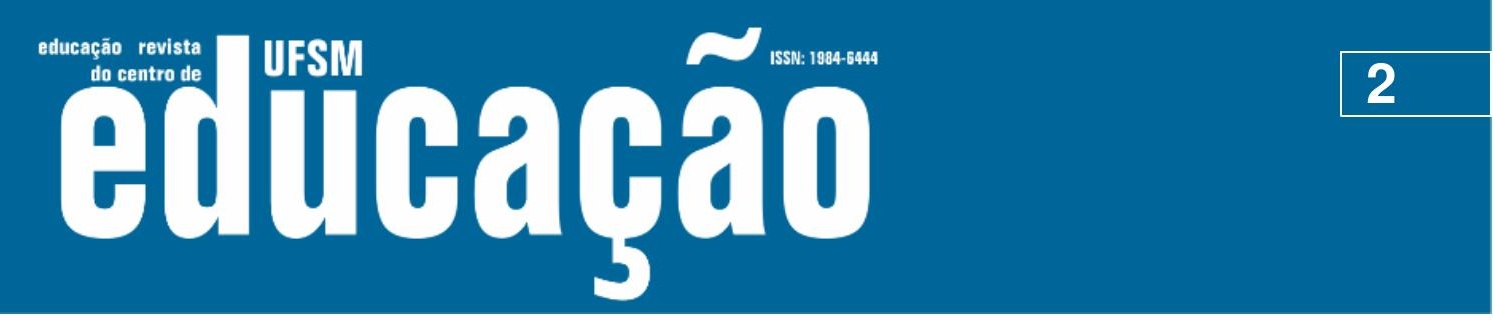

ISSN: 1984-6444 | http://dx.doi.org/10.5902/1984644436458

\section{ABSTRACT}

The focus of this paper is to discuss the emergence of Brazilian women's voices in contemporaneity - from the condition of silence and inferiorization of "subalterns", to the disruptions and, consequently, speeches and manifestations in both digital networks and the streets. In this paper, we propose a debate on the following questions: How has the passage from women's silence to their speech in public spaces occurred? From which conditions? We used \#EleNão (2018) movement as our corpus for analysis. The Foucauldian perspective of discursive event inspired the theoreticalmethodological path for analysis. From the analyses, we can highlight that \#EleNão movement has re-updated the struggle for acknowledgement of the other in politics She. \#EleNão has emerged as politics of performativity, bodily and gestural actions of resistance, and display of the right to speak, to appear in the sense of existing, to fight against the precariousness of existences. \#EleNão has produced meanings of political action in the Brazilian social imagery, that is, it has repositioned a kind of leave from women's condition as voiceless subaltern beings. \#EleNão has become a space to problematize/think about feminism in the interstices of its equalities and differences in the field of gender relations.

Keywords: Women; Speech; Acknowledgment.

\section{Da condição de silêncio da inferiorização às fraturas: falas das "subalternas"}

No final de um almoço com a família, já no período do segundo turno das eleições brasileiras de 2018, afirmamos: "[...] fizemos votos escolhendo as candidatas mulheres"! Isso gerou um caloroso conflito entre mulheres e homens presentes. Imediatamente, fomos levadas a pensar: "[...] o que, efetivamente somos e o que as candidatas em quem votamos são?" Mentalmente, sobreveio-nos a resposta, cruel e implacável: "somos mulheres ${ }^{1 "}$.

Observamos e sentimos, no teor das discussões, que somente os homens podiam participar das discussões políticas e, ainda, que a presença feminina "desequilibra" o jogo na política. Parece que a orientação de misoginia não é espontânea quando se trata de política, do espaço de fala, da tomada de posições. Perguntamos: as mulheres que tomam posição teriam rompido com algum código de gênero por defenderem perspectivas políticas e opinarem sobre questões nesse campo? Somos mulheres, e aí? Não podemos votar em quem quisermos? 


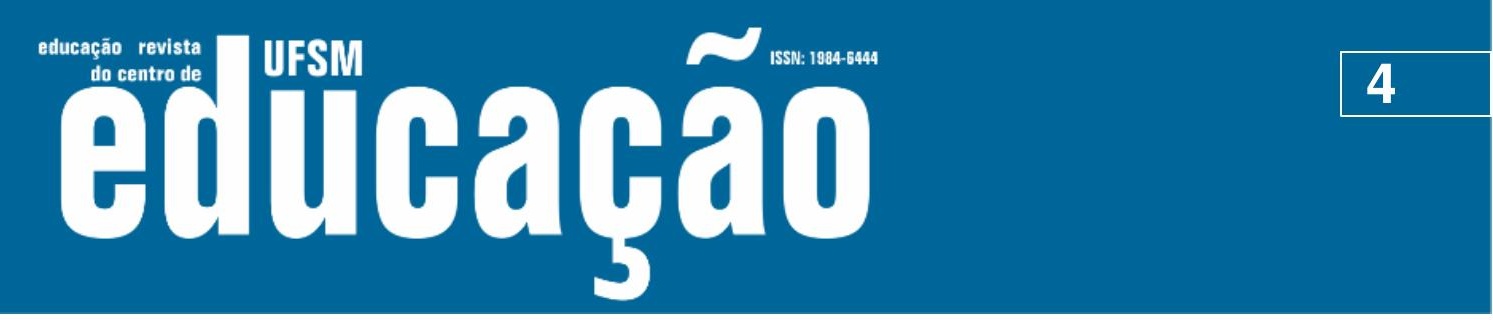

ISSN: 1984-6444 | http://dx.doi.org/10.5902/1984644436458

Spivak (2010) discorre também sobre o silêncio das mulheres, enfatizando que a mudez feminina faz ver a necessidade do reposicionamento das mulheres no espaço social. Com esta afirmação, Spivak (2010) diz que alguns sujeitos têm roubada a sua faculdade de enunciação sobre si e sobre o mundo; são sujeitos a priori desqualificados do lugar de fala. Ao refletir sobre as mulheres como sujeitos subalternos, Spivak (2010) explicita a marginalidade destas na cena pública. Tal posição está em consonância com a de muitas teóricas feministas ${ }^{3}$, que destacam 0 público como tradicionalmente arena ou lugar do masculino.

As novas redes digitais e seus embates parecem tensionar essa questão do silêncio, de modo que paira a seguinte questão: "as subalternas podem falar" (SPIVAK, 2010, p. 10)? Na contemporaneidade, as mulheres, que historicamente não tiveram poder de fala, podem instaurar falas, entrar no diálogo político.

Este artigo é fruto dessas provocações iniciais e visa a problematizar como tem se dado a passagem entre o silêncio e as falas das mulheres nas redes digitais, considerando-se os espaços públicos da política. Para tanto, utilizamo-nos das análises de discursos publicizados na rede social Facebook (2018), especialmente no grupo do movimento \#EleNão, nomeado de Mulheres Unidas Contra Bolsonaro (MUCB).

\section{Princípios teórico-metodológicos para análise do acontecimento discursivo \#EleNão}

Inspiramo-nos na análise do discurso a partir da perspectiva foucaultiana (FOUCAULT, 2009), que compreende a produtividade material dos acontecimentos discursivos, como a do movimento \#EleNão. A análise do discurso reconhece os acontecimentos a partir da linguagem produzida e dos sentidos, operando em prol das significações e dos valores discursivos. Além disso, considera a materialização dos discursos o funcionamento enunciativo.

As formações enunciativas, posição ou conjuntura discursiva, definem o que pode e deve ser dito e/ou articulado em um discurso. As formações enunciativas assumem papel relevante, pois "[...] materializa[m] o discurso e os sentidos, digo que 


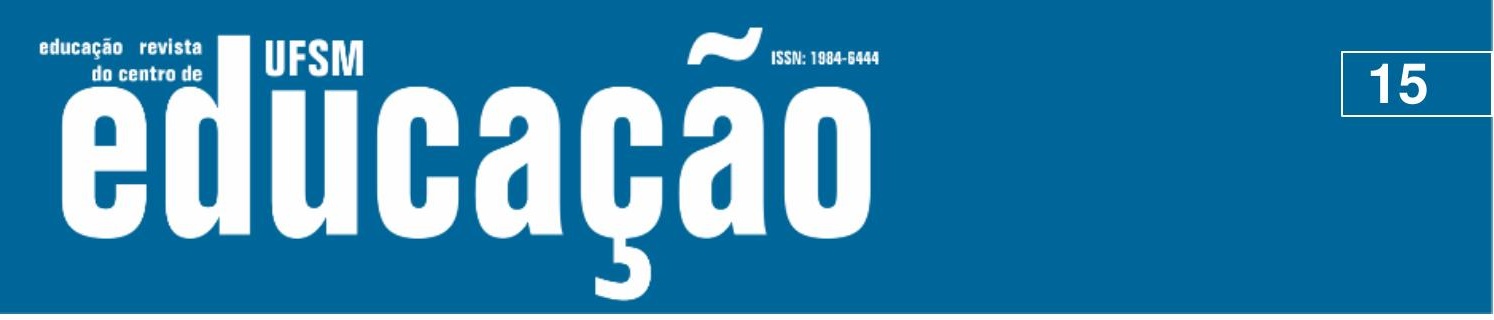

ISSN: 1984-6444 | http://dx.doi.org/10.5902/1984644436458

O movimento \#EleNão emergiu como um movimento entre as redes digitais e nas ruas das diferentes cidades brasileiras. Tomando as referências de Butler (2018), é possível dizer que esse movimento reinventa o gênero feminino ao reivindicar o direito de aparecer, de falar, de manifestar-se sobre a política. Ratifica o reconhecimento e a existência, no caso, das mulheres, enquanto sujeitos políticos com direito de aparecer publicamente.

O \#EleNão, escavado pelo direito de falar, demonstra que a luta das mulheres está apenas começando. Estão se deslocando do lugar de subalternas, compreendendo o direito dos "lugares de fala", de falarem juntas, de fazerem um "eco coletivo". Apresentar-se nas redes e nas ruas, na luta pelos seus direitos, é um movimento que não tem volta, pois as mulheres se colocam para questionar a própria precarização das condições de existência. É o coletivo que clama: "estamos aqui, existimos, demandamos" (BUTLER, 2018, p. 124). "Bora" falar, "bora" não fraquejar.

\section{Referências}

AGÊNCIA BRASIL. IBGE: mulheres ganham menos que homens mesmo sendo maioria com ensino superior. Disponível em: http://agenciabrasil.ebc.com.br/geral/noticia/2018-03/ibge-mulheres-ganham-menosque-homens-mesmo-sendo-maioria-com-ensino-superior. Acesso em: 10 nov. 2018.

BUTLER, Judith. Corpos em Aliança e a Política das Ruas: Notas Sobre Uma Teoria Performativa de Assembleia. Trad. Fernanda Siqueira Miguens. São Paulo: Civilização Brasileira, 2018.

CARRILLO, Jesús. Entrevista com Beatriz Preciado. Cadernos Pagu, Campinas, n. 28, jun. 2007. Disponível em: https://www.scielo.br/pdf/cpa/n28/16.pdf https://www.scielo.br/pdf/cpa/n28/16.pdf. Acesso em 10 nov. 2018.

FACEBOOK. Disponível em: https://www.facebook.com/. Acesso em: 10 nov. 2018.

FOUCAULT, Michel. As palavras e as coisas. Uma arqueologia das ciências humanas. 1. ed. Lisboa: Portugalia, 1998.

FOUCAULT, Michel. A ordem do discurso. 18ª ed. São Paulo: Loyola, 2009.

HOLLANDA, Heloisa Buarque de. Explosão feminista: arte, cultura, política e universidade. 1. ed. São Paulo: Companhia das Letras, 2018. 


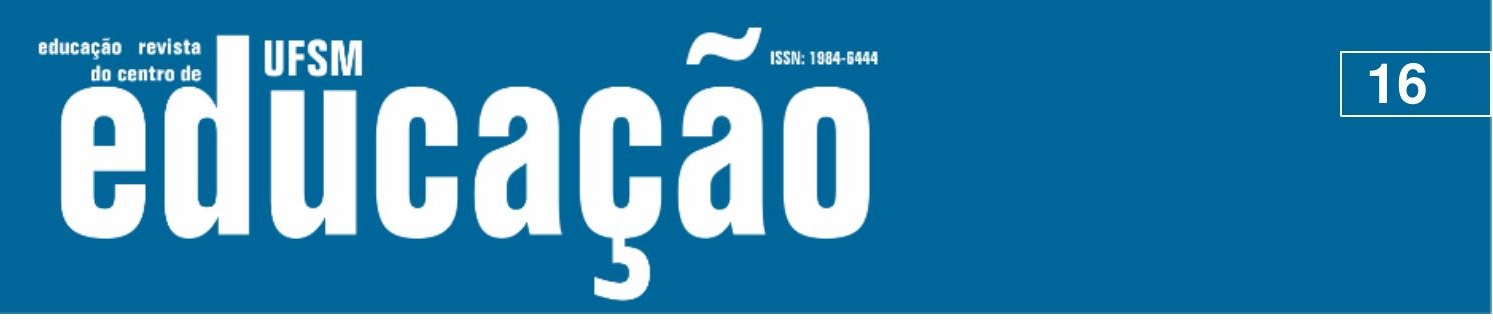

ISSN: 1984-6444 | http://dx.doi.org/10.5902/1984644436458

HOOKS, Bell. Feminism Is for Everybody: Passionate Politics, Cambridge, MA: South End Press, 2000.

MACKINNON, Catharine A. Feminism unmodified: discourses on life and law. Cambridge-Massachusetts: Harvard University Press, 1987.

MICHAELIS, Dicionário On-line. Subalterno. Disponível em: https://michaelis.uol.com.br/moderno-portugues/busca/portugues-

brasileiro/subalterno/. Acesso em: 10 nov. 2018.

OKIN, Susan Moller. Gênero, o público e o privado. Estudos feministas, Florianópolis, $\quad$ n. 2, mai. 2008.2 Disponível em: https://periodicos.ufsc.br/index.php/ref/article/view/S0104026X2008000200002/8618. Acesso em: 10 nov. 2018.

PERROT, Michele. As Mulheres e os silêncios da História. Bauru, SP: EDUSC, 2005.

SPIVAK, Gayatri Chakravorty. A Critique of Postcolonial Reason: Towards a History of the Vanishing Present. Cambridge: Harevard university Press, 2010.

SPIVAK, Gayatri Chakravorty. Critica del aragione postcoloniale. Roma: Meltemi, 2004.

SPIVAK, Gayatri Chakravorty. Pode o subalterno falar?. Tradução de Sandra R. Goulart Almeida; Marcos Feitosa; André Feitosa. Belo Horizonte: Editora UFMG, 2014.

\section{Correspondência}

Maria Simone Vione Schwengber - Universidade Regional do Noroeste do Estado do Rio Grande do Sul - Rua do Comércio, 3000, Bairro Universitário, CEP 98700 000, ljuí, Rio Grande do Sul, Brasil.

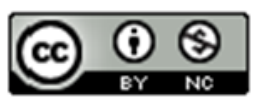

This work is licensed under a Creative Commons Attribution-NonCommercial 4.0 International (CC BY-NC 4.0)

\section{Notas}

\footnotetext{
${ }^{1}$ Partimos desse pressuposto tendo em conta que "mulher" não é uma referência monolítica, mas lugar de um conjunto de diferentes experiências complexas e potencialmente contraditórias, definido por variáveis que se superpõem, tais como classe, etnia, geração, escolaridade, religião, estilo de vida e preferência sexual, entre outras. Conforme Spivak (2000), "mulher” não como categoria biológica, nem sequer sociológica, e sim como um ponto de encontro (e às vezes de desencontro) entre o simbólico, o físico e o sociológico.
} 
